\title{
DISTRIBUIÇÃO DA TEMPERATURA NA SUPERFÍCIE DO MAR OBTIDA ATRAVÉS DO USO DE SENSORES REMOTOS NA ÁREA COMPREENDIDA ENTRE ITANHAÉM E A ILHA DE SÃO SEBASTIÃO (SP)
}

YOSHIMINE IKEDA E NUNO PEREIRA FILHO

Instituto Oceanográfico, Universidade de São Paulo, SP, Brasil

\section{SYNOPSIS}

The use of remote sensing in oceanography, has been largely increased, mainly because the synoptic look, the accuracy of the data as well as the economics aspects. This paper shows the features and the first results of some experiments performed in the offshore region near Santos Bay and São Sebastiāo Island, in the southeast coast of Brazil. The technique seems to be powerfull in coastal circulation studies, as well as, in every process that uses the temperature as a natural tracer. The tide currents seem to have large influence in the area near the Santos Bay, with a surface mean speed of about $1.2 \mathrm{~m} / \mathrm{s}$, which can reach distances of about $50 \mathrm{n} . \mathrm{m}$. One can note that the area can be divided, at least in surface terms, in two subareas, with different thermal behaviours, with the interface standing normal to the coast in front of Santos.

\section{Introduçầo}

Esta contribuiçâo apresenta os resultados preliminares da utilização de um radiômetro de precisão (PRT-5) instalado a bordo de aviōes de pequeno porte (Cessna 180) na deteç̧ão da temperatura da superfície do mar.

A experiência em questão, foi levada a efeito nos dias 07/06/1977, 08/06/1977 e 27/01/1978, na região costeira, não superando $120 \mathrm{mn}$ de distância à costa, se extendeu desde Itanhaém até pouco além da Ilha de São Sebastião (Figs. 1, 2 e 4).

$O$ equipamento utilizado denomina-se PRT-5 (Precision Radiation Thermometer), que se fundamenta na propriedade física da matéria de emitir radiações eletro-magnéticas (REM) dentro de amplo espectro e cuja intensidade energética é proporcional ao seu estado térmico.

Devido a vários fatores de ordem técnica, esse PRT-5 está dotado de um dispositivo denominado sensor, situado dentro do que chamamos Cabeça Óptica, que detecta apenas uma parcela do espectro eletro magnético, compreendida entre 9.5 e $11.5 \mathrm{~m} \mu$ (milimicron).

Esses cumprimentos de onda se situam dentro de uma faixa de espectro denominada infra-vermelho (IV), que é menos susceptível à interferência de elementos encontrados no ar atmosférico, tal como vapor d'água e $\mathrm{CO}_{2}$.

A REM detectada pelo sensor é transformada em sinal elétrico, que será amplificado em outro dispositivo denominado Unidade Eletrônica e finalmente registrado de modo apropriado em fita de papel, de modo contínuo, na Unidade Eletrônica e finalmente registrado de modo apropriado em fita de papel, de modo contínuo, na Unidade Registradora. A precisão dos dados, segundo a Barnes Engineering Co (USA) é da ordem de $0,5^{\circ} \mathrm{C}$, a qual pudemos realmente verificar durante a calibração do mesmo em nosso laboratório.

$\mathrm{O}$ aparelho assim descrito, foi instalado a bordo de um avião Cessna 180 , onde vários cuidados foram observados, por se tratar de um aparelho monomotor.

\section{Metodologia}

Na obtenção đas distribuições térmicas (Figs. 1, 2 e 4) a metodologia adotada foi a seguinte:

1) calibração do aparelho em laboratório, com levantamento de sua curva de calibração;

2) preparo apurado de carta para navegaçāo com anotações de todos-os pontos de referência visuais, tempos e direções teóricas a serem seguidos, conferidos e observados durante a realização do vôo; estabelecimento de pontos, onde fosse possivel a verificação da posição do avião, em função dos rádios faróis existentes ao longo da costa;

3) durante a realização do vôo, todas as previsões eram conferidas constantemente, e as distorções ou variações observadas eram anotadas;

4) finda a operação de vôo, o equipamento foi novamente levado ao laboratório, para verificação da calibração e levantamento de nova curva. De posse desses dados, fo possível a interpretação do registro obtido. As anotações dos desvios e distorções permitiram o levantamento do que cremos ser a rota mais provável, dentro do índice de precisão aceito para navegação aérea sobre o mar;
5) de posse dos dados referente à posição do avião e do registro de temperatura convenientemente digitalizados, foi possível a confeç̧ão das referidas cartas de distribuição térmica das águas superficiais, dentro das técnicas usuais de oceanografia física.

\section{Análise dos Dados}

Da simples observação das Figuras 1, 2 e 4, podemos verificar a potencialidade da técnica em termos da sinopticidade das informações, pois cada vôo não teve duração superior a 2,5 horas. Evidentemente fica claro, como se pode observar principalmente pela Figura 1, que o distanciamento entre as radiais é um fator limitante, pois, em se tratando de região muito próxima à costa, as variaçōes podem ser bastante pronunciadas e um distanciamento maior, como ocorre entre as duas primeiras radiais do vôo do dia $07 / 06 / 77$ (Fig. 1), não nos proporciona informaçōes suficientes, para a construção do mapa da distribuição térmica. Evidentemente, se estivermos tratando de uma região termicamente menos conturbada, um espaçamento maior pode ser perfeitamente viável. Para a região em questão, devido à grande variabilidade de temperatura de superfícies, pelo menos para esta época do ano, acreditamos ser necessário um distanciamento entre as radiais não superior a $8 \mathrm{mn}$, para que se tenha uma boa idéia da distribuição dessa propriedade.

Na Figura 2, devido à configuração mais apropriada da distribuição térmica, podemos observar uma boa demonstração da influência de águas interiores, que provavelmente devido à corrente de maré, que permitiu a saída de grandes quantidades de águas, mais aquecidas, que se situavam dentro do complexo estuarino de Santos e sua respectiva bacia. A Figura 3, mostra-nos o comportamento da maré (D. H. N., 1977), nos dias e horas correspondentes aos dois vôos, na região de Santos. Fica bem evidente que a ocorrência detectada pelo vôo do dia 08/06 (Fig. 2), se deu em um período bem próximo ao fim de uma maré vazante, cuja variação de altura foi de aproximadamente $0,6 \mathrm{~m}$ durante um intervalo de tempo de $08 \mathrm{~h}$, portanto, uma variação bastante lenta. Admitindo-se que, os valores mais elevados da temperatura sejam de águas interiores à região do Porto e estuário, podemos estimar que a velocidade média das águas da superfície para este evento são da ordem de $1,2 \mathrm{~m} / \mathrm{s}$.

A Figura 1, embora um tanto incompleta no que diz respeito às isotermas ao sul de Santos, mostra-nos uma distribuição cuja variabilidade é bastante grande $\Delta \mathrm{T} \simeq 5,0^{\circ} \mathrm{C}$ (o mesmo não ocorria para o caso anterior, onde a temperatura externa ao "leque" era da ordem de 23,5 a $24,0^{\circ} \mathrm{C}$ ) que evidencia um fluxo de águas perpendicular à costa, não sendo, contudo, possível adiantar se este fluxo se dirige para a costa ou se afasta dela. Este tipo de distribuição térmica para essa região, em termos de uma coluna vertical, mostra ser essa região fronteira a Santos, uma interface entre águas de estados térmicos e comportamentos diferentes, uma situando-se ao norte e outra ao sul dessa interface (Pereira Filho, 1980), assim podemos observar que as águas situadas ao norte, apresentam temperaturas mais elevadas $\left(26-27-28^{\circ} \mathrm{C}\right)$ enquanto que ao sul, podemos observar temperaturas entre 22 e $24,5^{\circ} \mathrm{C}$.

Do exemplo, se tomarmos a isoterma de $26,5^{\circ} \mathrm{C}$ (Fig. 1), verificamos, que esta se estende continuamente desde bem próximo à costa, na região de Guarujá e Bertioga até os limites externos 


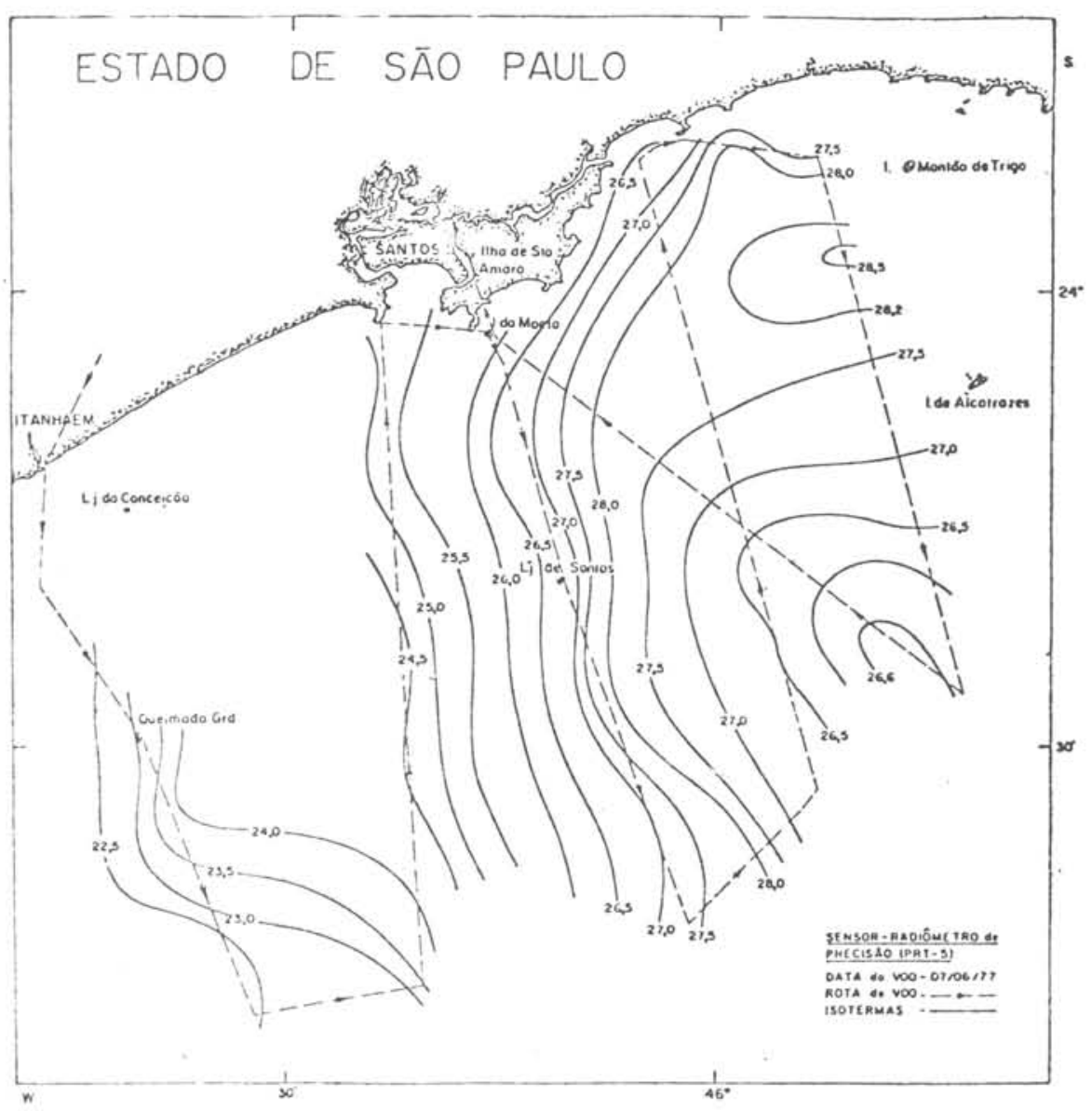

Fig. 1. Distribuiçāo de temperatura de superfície do mar para o dia 07/06/1977.

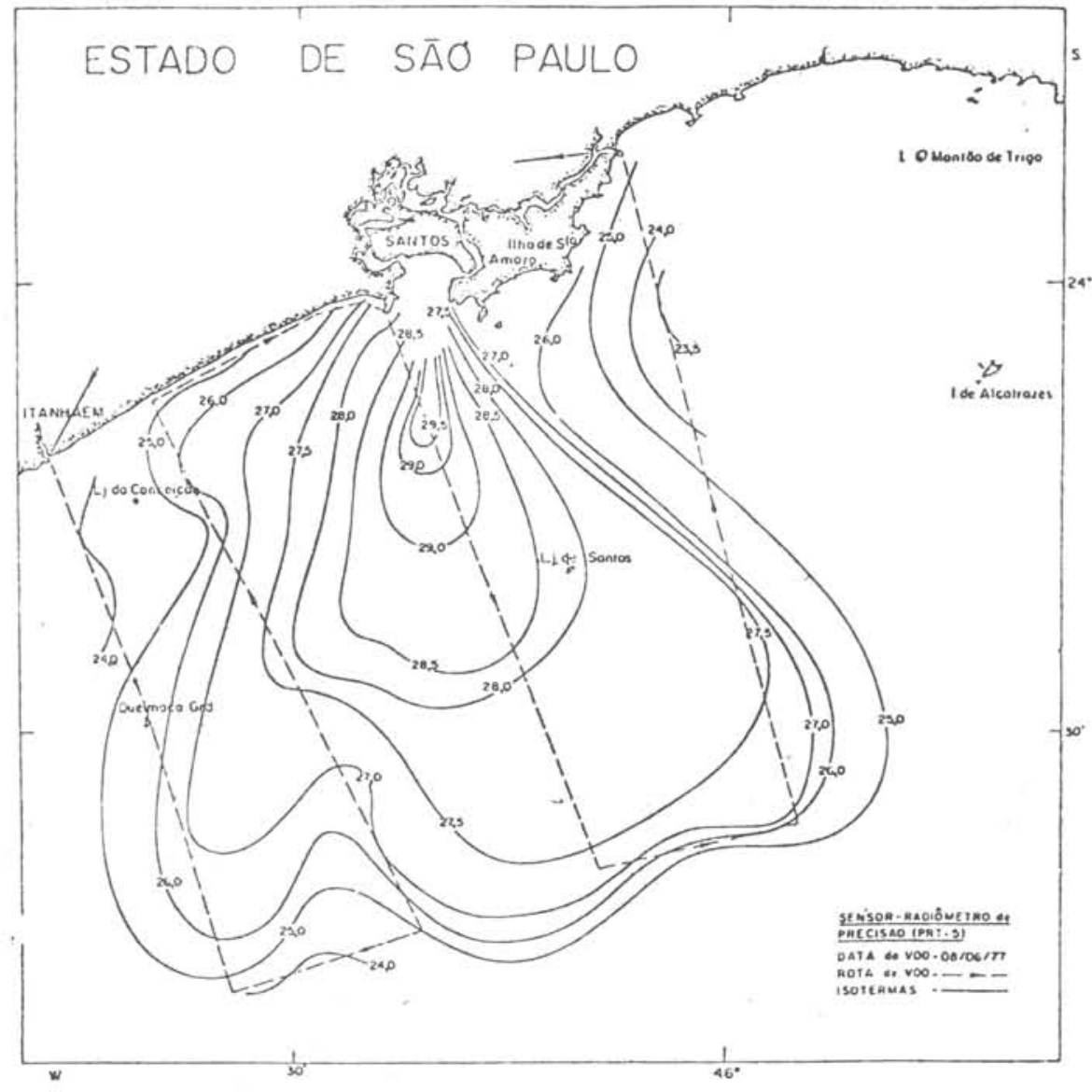

Fig. 2. Distribuição de temperatura de superfície do mar para o dia 08/06/1977. 


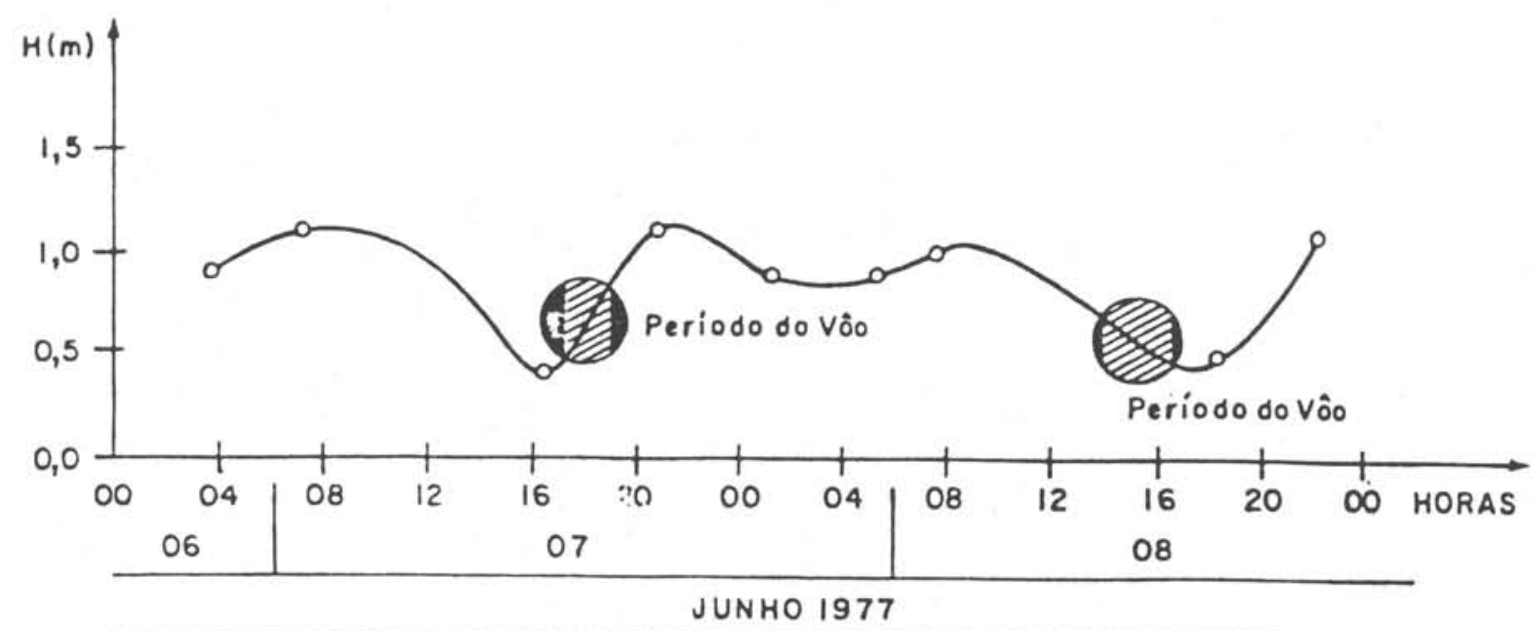

Fig. 3. Variação do nível do mar para os dias 07 e 08 de junho de 1977 (D.H.N., 1977).

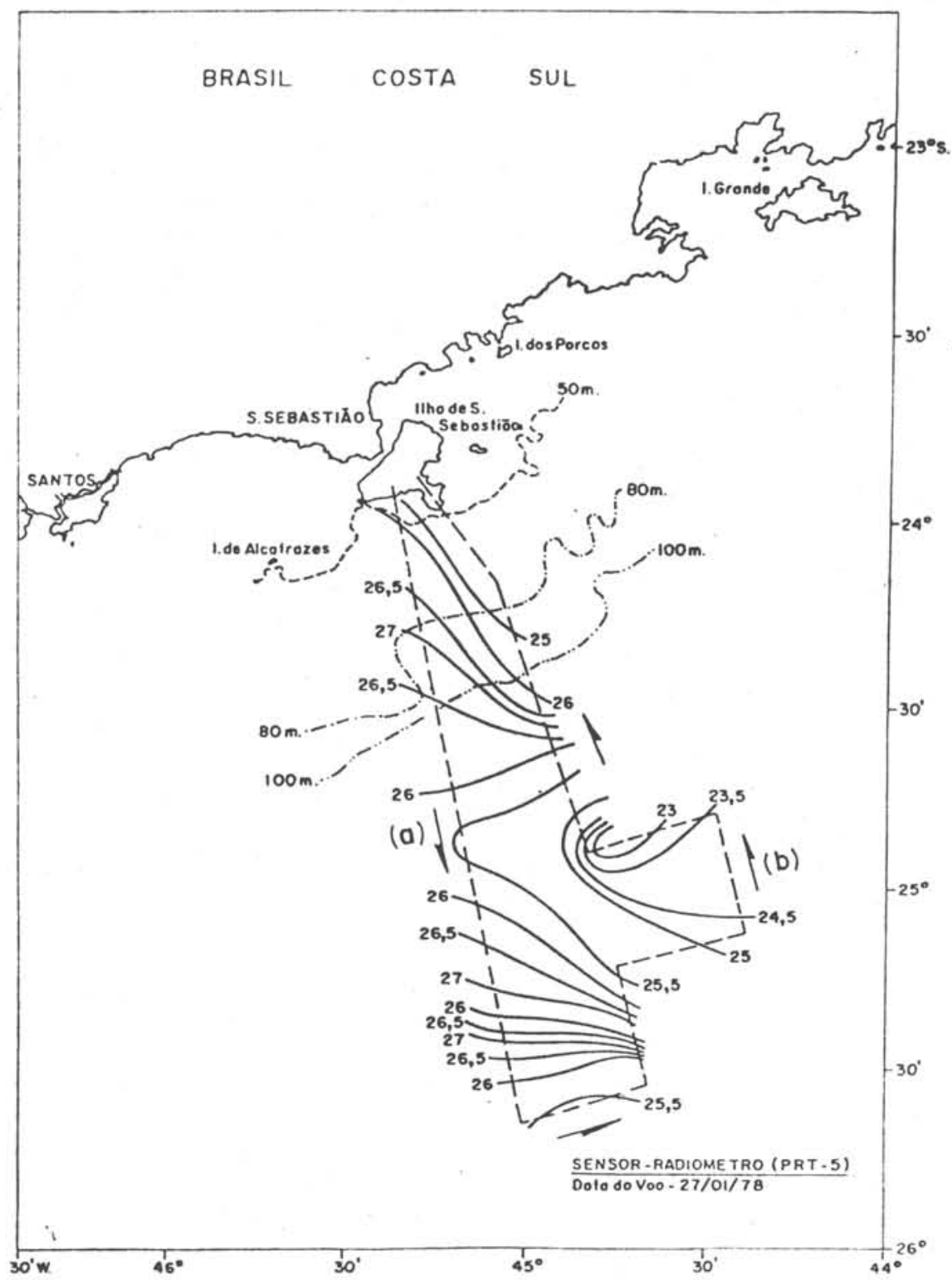

Fig. 4. Distribuição de temperatura de superfície do mar para o dia 27/01/1978. 


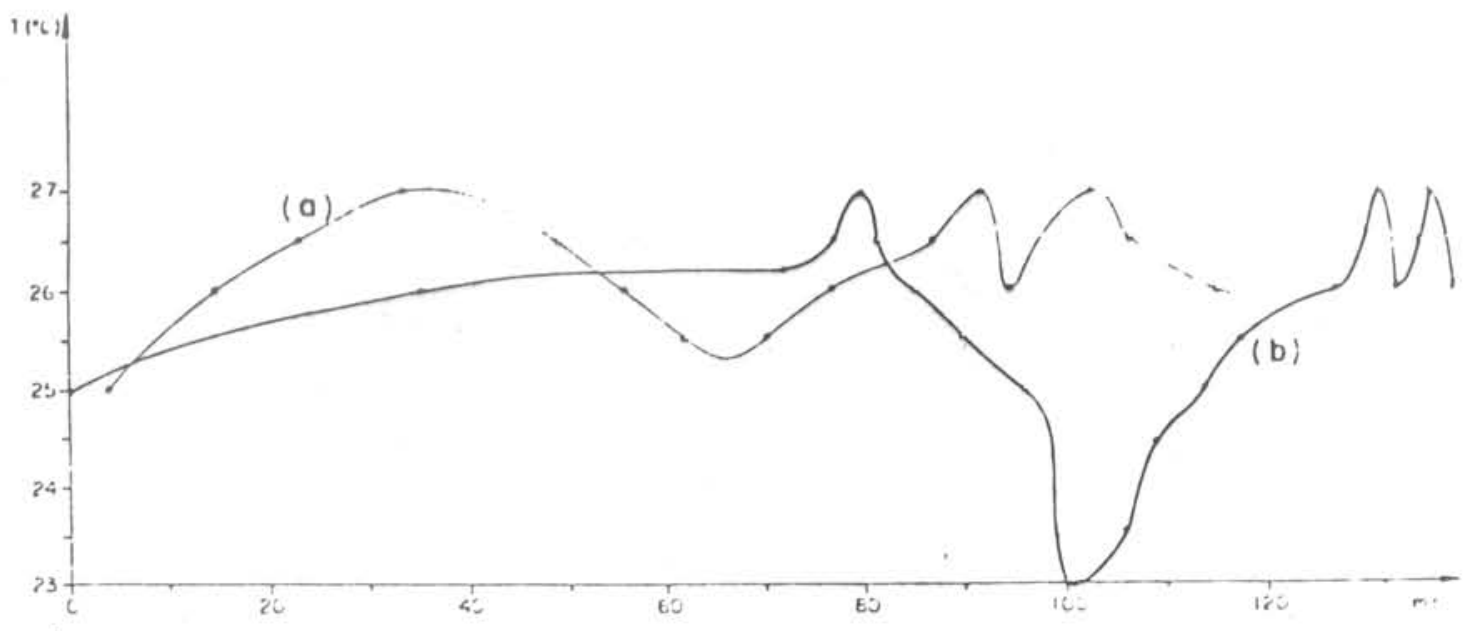

Fig. 5. Variação da temperatura para as radiais (a) e (b) do dia 27/01/1978.

da area amostrada. No nosso entender, tal configuração parece nos sugerir um giro anti-horário, para a região ao norte de Santos, sendo porém necessário maior número de observações para sua efetiva verificação.

As Figuras 4 e 5 nos apresentam a distribuiçāo térmica para a região fronteiriça à Il tha de São Sebastião e a variabilidade dessa propriedade para as águas de costas. Observamos que a primeira radial (Fig. 4) varia entre 25,5 a $27^{\circ} \mathrm{C}$ em quase toda a região, atingindo $25,5^{\circ} \mathrm{C}$ no limite externo da área, isto é, por volta de $130 \mathrm{mn}$ da costa. Para a segunda (retorno), foi executado um desvio de $10 \mathrm{mn}$ para o norte retornando-se à linha original $10 \mathrm{mn}$ mais adiante, e foi registrada uma variabilidade de $4,0^{\circ} \mathrm{C}$ (Fig. 4) compreendida entre $23^{\circ} \mathrm{C}$ e $27^{\circ} \mathrm{C}$. Casualmente, na região onde foi feito o desvio, com o objetivo de melhor aproveitar o vôo, deparamos com uma configuração das isotermas, sugerindo um vórtice ou um núcleo de águas frias, cujo nível térmico é bem inferior ao de águas adjacentes. E difícil fazer considerações acerca da origem dessa água, devido principalmente à falta de mais infomações.

Conchusão

Os resultados aqui apresentados evidenciam que esta técnica é altamente eficiente para uma série de atividades oceanográficas, devido à rapidez em cobrir grandes áreas, o que possibilita um excelente grau de sinopticidade, principalmente para melhor compreensão da circulação de águas.

Em todos esses casos, cabe-nos frisar que, a temperatura, sendo um elemento traçador, sempre que esta propriedade puder ser utilizada como tal, pode-se lançar mão dessa técnica. (Stevenson et al., 1979) A realização de vôos metódicos e sistematicamente programados pode permitir o conhecimento térmico de uma área qualquer, bem como a detecção e acompanhamento de fontes de poluiçã̃o térmica em áreas oceânicas. Acreditamos que essa técnica possa ser de grande auxílio para a pesca de espécies de peixes condicionados a condições térmicas de águas bem definidas. Esta técnica, acompanhada de observaçōes visuais de cardumes pelágicos foi executada por Ikeda \& Pereira Filho (1978).

A análise dos resultados nos sugere uma profunda influência das correntes de maré, pelo menos em termos de águas superficiais, na região fronteira à Baía de Santos. Entretanto, é necessário a realização de um programa sistemático de vôos, para a obtenção de mais informações.

Foi-nos possível observar a ocorrência de duas áreas próximas a Santos, de comportamentos térmicos diferentes, cuja interface se desenvolve perpendicularmente à costa em frente a Ilha de Santo Amaro, o que vem corroborar o fato verificado por Pereira Filho (1980).

Cumpre-nos destacar o fato de que as configuraçōes verificadas nas Figuras 1 e 2 são extremamente diferentes, para um intervalo de tempo inferior a 24 horas, entre a obtenção de cada uma, o que nos leva a pressupor fatores de grande eficiência que alteram as características térmicas dessa área. Este fato nos mostra a necessidade de um estudo maior dessa região, para a obtenção simultânea de outras informaçōes.
Estes vôos foram realizados com suporte financeiro do Subprojeto Biologia da Pesca/FINEP e da Secretaria de Ciência, Cultura e Tecnologia do Estado de São Paulo.

\section{Resumo}

A utilização de sensores remotos em oceanografia tem sido amplamente aumentada principalmente devido aos aspectos sinópticos, ao aumento da precisão das informaçð̄es bem como do aspecto econômico.

Este trabalho apresenta as características e os resultados primários de alguns vôos executados sobre o mar na região próxima a Santos e Ilha de São Sebastião, na costa sudeste do Brasil.

A técnica mostrou-se eficiente na verificação dos processos de circulação costeira, bem como em qualquer processo em que se utilize a temperatura como traçador.

As correntes de maré parecem exercer grande influência na área próxima a baía de Santos, onde uma velocidade superficial média da ordem de $1,2 \mathrm{~m} / \mathrm{s}$ foi estimada, e essa influência pode se estender à distância da ordem de $50 \mathrm{mn}$.

Podemos observar também a possível divisão da área, pelo menos superficialmente, em duas sub-áreas, com comportamentos térmicos diferentes, cuja interface se desenvolve normalmente à costa em frente a Santos.

\section{Agradecimentos}

Ả srta. Marilza Correia, pela paciência com que prestou os serviços de datilografia, aos srs. Marco Antonio Montalban e Osmar Mariano Pires de Campos pela dedicação nos desenhos, e montagens.

\section{BIBLIOGRAFLA}

DIRETORIA DE HIDROGRAFIA E NAVEGAÇĀO, Rio de Janeiro.

1977. Tábua de Marés.

IKEDA, Y \& PEREIRA FILHO, N.

1978. Distribuições térmicas, salinas, topo e fundo das termoclimas e de cardume pelágicos (Cabo Frio-RJ à Cabo de Santa Marta Grande-SC, Nov/75 a Fev/78). Brasília, Secretaria do Planejamento da Presidência da República (FINEP) Instituto Oceanográfico da USP. Relatório do Sub-Projeto Biologia da Pesca, vol. II, partes A e B, p. 1-288

PEREIRA FILHO, N.

1980. Contribuição ao estudo das características térmicas da região oceânica compreendida entre a Ilha de São Sebastião (SP) e Cananéia (SP). Dissertação de Mestrado. Universidade de São Paulo, Instituto Oceanográfico, $116 \mathrm{p}$.

STEVENSON, M; SQUIRE, Jr, J.; BOOTH, C. \& IKEDA, Y.

1979. Use of airborne radiometers for monitoring sea surface temperature and chlorophyll in a coastal fishing zone. CalCOFI Rep. vol. 20:138-142. 